\title{
MODEL OF LACTIC ACID FERMENTATION OF BULGARIAN YOGURT
}

\author{
Kaloyan Yankov, Miroslav Vasilev, Krasimir Nikolov \\ Faculty of Technics and Technologies, Trakia University, Bulgaria \\ 38 Graf Ignatiev Str., 8600 Yambol, BULGARIA \\ e-mail: kaloyan.yankov@trakia-uni.bg
}

\begin{abstract}
Model of the dependence of active resistance of milk during the fermentation as a function of the butterfat content and titratable acidity is created. Formulas for the range of the resistance of the medium at which should be interrupted lactic acid fermentation are deduced. A program module for calculating and displaying of the graphs of resistance change for arbitrary fat content is created. The model is applicable to yogurt produced according to requirements of the Bulgarian State Standard.
\end{abstract}

Keywords: yogurt, lactic fermentation, system identification, mathematical model.

\section{INTRODUCTION}

Yogurt is a nature food, including proteins, essential fatty acids, lactose, and minerals in balanced proportions. It enhances cellular and antibody functions of the immune system, resulting in an increase of resistance to infections, cancer, allergies, and gastrointestinal disorders [3]. Obtaining and properties of yogurt due to the symbiosis of two bacteria: Lactobacillus delbrueckii ssp. Bulgaricus and Streptococcus thermophilus. The first of them was identified in 1905 by Bulgarian doctor Stamen Grigorov, who named it Bacillus Bulgaricus. The full name of the bacterium is now "Lactobacillus delbureckii subsp. Bulgaricus Grigoroff 1905". It is typical for Bulgaria by participating in receipt of other areaspecific naturally fermented products. Yogurt bacteria are included in the list of probiotic cultures because they possess a distinctly high lactase activity, making yogurt easily digestible by individuals with a lactose-maldigestion condition.

Yogurt is widespread food product which can be produced with different technologies. To have a repeatability of the taste and to create a long shelf-life food, a number of technological parameters must be observed very precisely. Yogurt mix preparation, heat treatment, fermentation conditions, and post-fermentation microbiological characteristics all have a great impact on product taste and quality [2,15]. Traditions in the production and repeatability of taste characteristics of Bulgarian yogurt (in Bulgarian language: "kiselo mliako") in Bulgaria has legalized a State standard for production, storage, and transportation of the product: Bulgarian State Standard "BDS 12:2010 Bulgarian Yogurt" [1]. Regardless of the number, the type and nature of these parameters, the final result of their total effect is the acidity of the product. The acidity is a result of the action of these specific bacteria and affects taste, the durability of the product, its usefulness, and the measured numerical value is an accurate test for the finishing of the process of lactic acid fermentation. Thus this parameter is tested to determine the quality of the milk product. The milk acidity is also a means of monitoring the storage conditions because it increases over time.

During the fermentation process, the acidity of the medium is constantly increasing. To obtain a yogurt with the desired properties, it is necessary to interrupt and inhibit the fermentation when the specific acidity is reached. Therefore it is important to measure the acidity quickly and accurately. Direct measurement of the acidity is not appropriate from a technological point of view. A suitable approach is to measure an auxiliary parameter, which

IRTIIE Vol. 5, No. 4, 2017 ISSN 1314-8788 (print), ISSN 1314-8796 (online), doi: 10.15547/artte.2017.04.005 


\section{ART'TE $Y$}

Ipplied Resseirlohes in Technics, Technologies and Eductition

Journal of the Faculty of Technics and Technologies, Trakia University https://sites.google.com/a/trakia-uni.bg/artte/

has a high correlation with the acidity. In [4] the relationship between the relative change of active impedance component and the relative change of titratable acidity of the dairy environment in conditions of lactic fermentation is determined. In the same article, it was found that the rate of lactic acid fermentation depends on the butterfat content of milk. To automate the process of monitoring and identification of acidity as a function of resistance must be established a mathematical model of the process of acidification as a function of the fat content in milk.

The purpose of this work is to create a mathematical model of dependence "acidityresistance" in function of the butterfat content of cow's milk produced according to requirements of the Bulgarian State Standard. The model will enable automatic tracking and management of lactic acid fermentation of cow's milk.

\section{EXPERIMENTAL DESIGN}

There are two different conventions for expressing acidity in dairy products - titratable acidity $\boldsymbol{A}_{\boldsymbol{T}}$ and hydrogen ion concentration, or $\boldsymbol{p H}$. A widespread approach is the measuring of titratable acidity. Titratable acidity is expressed as one of a variety of units: ${ }^{\circ} \mathbf{S H}$ - Soxlet Henkel degrees, ${ }^{\circ} \boldsymbol{T h}$ - Thorner degrees, ${ }^{\circ} \boldsymbol{D}$ - Dornic degrees. Bulgarian State Standard "BDS 12:2010 Bulgarian Yogurt" recommends the usage of Thorner degrees. This standard regulates the parameters of the medium in the preparation of yogurt: the presence of strains of Lactobacillus delbrueckii ssp. bulgaricus and Streptococcus thermophilus, isolated in Bulgaria and not subjected to genetic modification, non-fat solids content, milk protein content, fat content, fermentation temperature, rate of cooling. The process of lactic acid fermentation should be stopped when the titratable acidity reaches $75-80{ }^{\circ} \mathrm{Th}$.

In accordance with the standard for four types of fat $2.4 \%, 3.2 \%, 4.3 \%$ and $5.2 \%$ was the experiment carried out. Corresponding graphs (Figure 1) with the results of the measurement of acidity and resistance of the four types of fat content in a raw product [4] are built. These data provide the basis for the process identification.

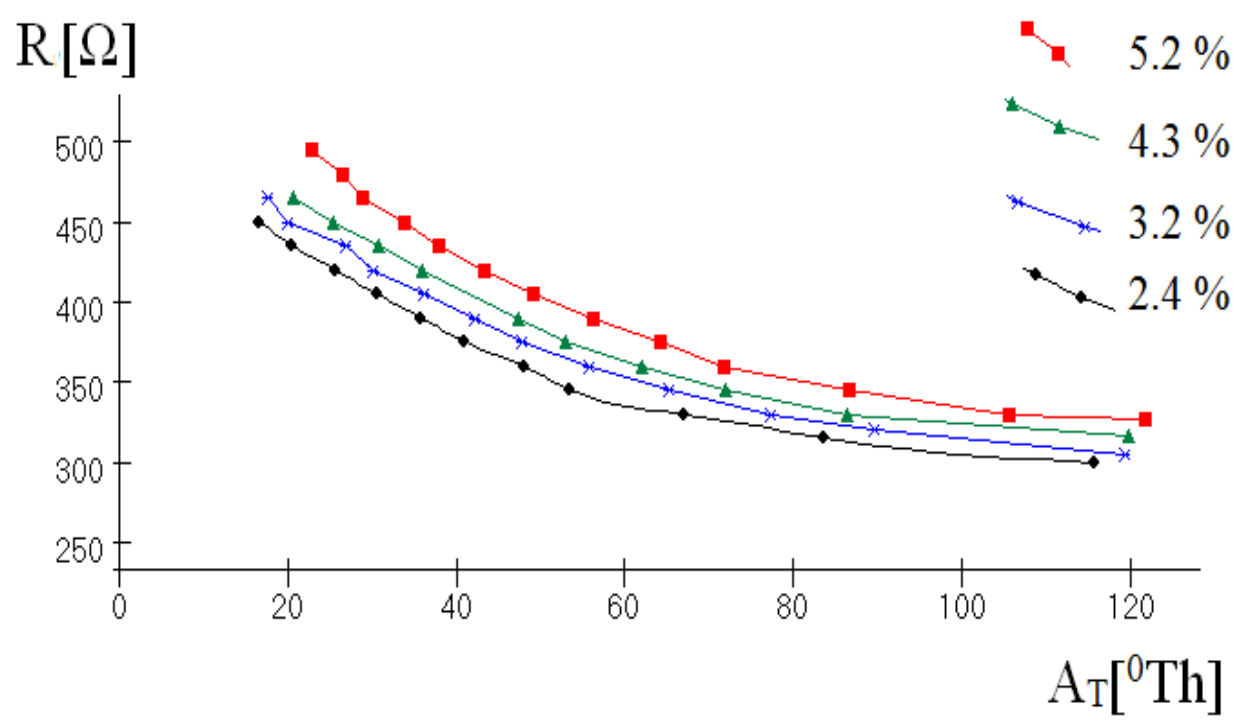

Figure 1. Spline interpolation of the relationship between electrical resistance and acidity in four types of butterfat. 


\section{ARTIIL

\section{MODEL IDENTIFICATION}

The identification of the mathematical model based on experimental data is made with the program Korelia $[6,10,11]$. The program has a user-friendly interface [13], conditioned by the availability of language for model description [7] and abilities for recognition of the examined process $[8,9]$. The identified processes can be analyzed and compared to a number of parameters [12] and thus be selected most appropriate for a particular data set [14]. Korelia program allows graphic visualization of data and results, as well as image analysis and processing [5].

The graphs show the change that can be identified by a downward exponent with equation:

$$
\begin{aligned}
& R\left(A_{T}\right)=\left(R_{0}-R_{\infty}\right) \cdot e^{-\frac{A_{T}+\beta}{A_{C}}}+R_{\infty} \\
& \text { where: } \mid \begin{array}{ll}
R\left(A_{T}\right)[\Omega] \text { - resistance in function of titratable acidity; } \\
A_{T}\left[\left[^{0} \mathrm{Th}\right]\right. & \text { - titratable acidity; } \\
A_{C}\left[{ }^{0} \mathrm{Th}\right] & \text { - acid constant of the process; } \\
R_{0}[\Omega] & \text { - resistance at acidity 0 }\left[{ }^{0} \mathrm{Th}\right] ; \\
\beta\left[{ }^{0} \mathrm{Th}\right] & \text { - acidity correction parameter; } \\
R_{\infty}[\Omega] & \text { - asymptote of the graph. }
\end{array}
\end{aligned}
$$

The parameters that must be identified specify the identification vector $Q$ :

$$
\mathrm{Q}=\mathrm{Q}\left(\mathrm{R}_{0}, R_{\infty}, \mathrm{A}_{\mathrm{C}}, \beta\right)
$$

This vector depends on the fat content of the product. Since the experiment was conducted for four kinds of milk, the identification will yield four different models. They should be integrated into a single model in which as an independent parameter must take part a fat content. The values of the identified parameters for the four cases are shown in Table 1. The butter-dependent values are graphically showed on Figure 2.

Table 1. Calculated values of the identification vector $\mathrm{Q}\left(\mathrm{R}_{0}, R_{\infty}, \mathrm{A}_{\mathrm{C}}, \beta\right)$

\begin{tabular}{|l|c|c|c|c|}
\hline \multirow{2}{*}{ parameter } & \multicolumn{4}{|c|}{ butterfat content [\%] } \\
\cline { 2 - 5 } & 2.4 & 3.2 & 4.3 & 5.2 \\
\hline $\mathbf{R}_{\mathbf{0}}[\Omega]$ & 425.88 & 403.63 & 426.00 & 432.80 \\
\hline $\mathbf{A}_{\mathrm{C}}\left[{ }^{0} \mathrm{Th}\right]$ & 40.56 & 49.54 & 43.60 & 36.40 \\
\hline $\boldsymbol{\beta}\left[{ }^{0} \mathrm{Th}\right]$ & -22.22 & -36.82 & -32.78 & -38.40 \\
\hline $\mathbf{R}_{\infty}[\Omega]$ & 285.71 & 278.18 & 295.20 & 315.76 \\
\hline
\end{tabular}

Graphs give reason the parameters $\boldsymbol{R}_{0}, \boldsymbol{\beta}$ and $\boldsymbol{R}_{\infty}$ to be identified with straight line equation:

$$
\begin{aligned}
y_{i}(b)=a_{i} \cdot b+c_{i} \\
\text { where: } \mid \begin{array}{l}
\mathrm{b}-\text { butterfat content } \\
y_{i}(b) \in\left[R_{0}, R_{\infty}, \beta\right], \mathrm{i}=1,2,3 \\
\mathrm{a}_{\mathrm{i}}, \mathrm{c}_{\mathrm{i}}-\text { parameters for } \mathrm{i} \text {-th model }
\end{array}
\end{aligned}
$$

IRTIIE Vol. 5, No. 4, 2017 ISSN 1314-8788 (print), ISSN 1314-8796 (online), doi: 10.15547/artte.2017.04.005 


\section{IRTTIE Ipplied Ressearches in Technics, Technologies ind Bdurition Journal of the Faculty of Technics and Technologies, Trakia University https://sites.google.com/a/trakia-uni.bg/artte/}

The parameter $\boldsymbol{A}_{\mathcal{C}}$ is suitable to identify with downward facing parabola with equation

$$
A_{C}(b)=k-\frac{(b-h)^{2}}{2 \cdot p}
$$

$$
\text { where: } \begin{aligned}
& (h, k) \text { - vertex of the parabola } \\
& p \text { - parameter }
\end{aligned}
$$

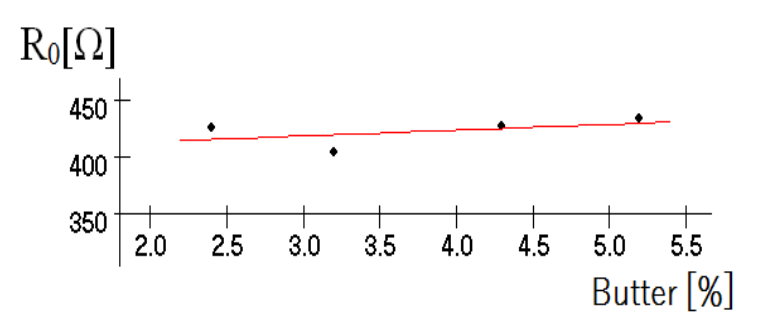

a) $\mathbf{R}_{\mathbf{0}}$

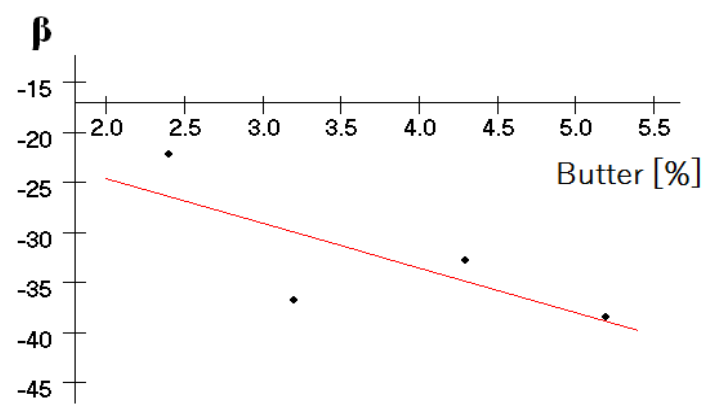

c) $\beta$

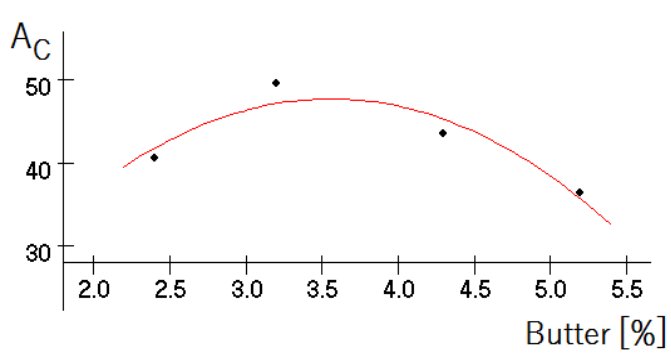

b) $\mathbf{A}_{c}$

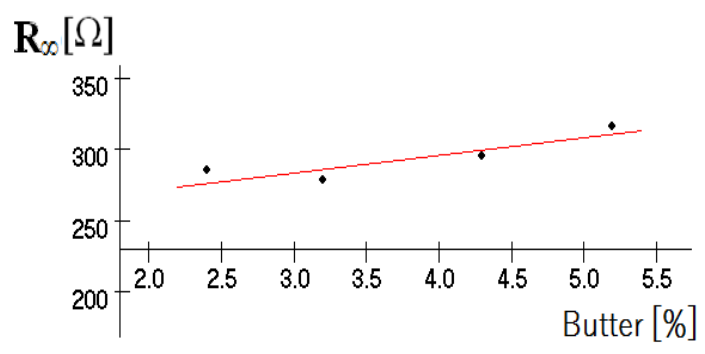

d) $R_{\infty}$

Figure 2. Graphical representation of the identification parameters

After the identification of the parameters in Table 1, together with the Eq.(1) the system of equations is obtained:

$$
\mid \begin{aligned}
& R_{0}(b)=5.027 b+403.104 \\
& R_{\infty}(b)=12.587 b+245.591 \\
& \beta(b)=-4.465 b-15.692 \\
& A_{C}(b)=47.762-\frac{(b-3.555)^{2}}{0.224} \\
& R\left(A_{T}\right)=\left(R_{0}-R_{\infty}\right) \cdot e^{-\frac{A_{T}+\beta}{A_{C}}}+R_{\infty}
\end{aligned}
$$




\section{ARTIL

This system determine the model of the impedance of the medium in lactic acid fermentation as a function of two independent parameters: butterfat content $\boldsymbol{b}$ and titratable acidity $\boldsymbol{A}_{\boldsymbol{T}}$. The algorithm that realized the model is shown in Figure 3. On Figure 4 are the graphs of the models.

According to the requirements of the standard, the fermentation should be stopped when the acidity is in the range $75-80^{\circ} \mathrm{Th}$. Based on the model the interval for termination of fermentation process as a function of the butterfat content can be built. The equations of the bounded lines are:

$$
\mid \begin{aligned}
& y_{75}(b)=12.64^{*} b+287.20 \\
& y_{80}(b)=11.78^{*} b+285.40
\end{aligned}
$$

Or:

$$
11.78^{*} b+285.40 \leq R(b) \leq 12.64^{*} b+287.20
$$

\begin{tabular}{|c|c|}
\hline $\begin{array}{l}\text { Procedure DrawAcidModel(const b : fl } \\
\text { const TFrs } \\
\text { var TStep } \\
\text { var Model } \\
\text { Var R0,Ri,Beta,Ac,At : float; } \\
\text { I, Nmb : word; } \\
\text { begin } \\
\text { R0:=5.027*b+403.104; } \\
\text { Ri: }=12.587^{*} \text { b+245.591; } \\
\text { Beta:=-4.465*b-15.692; } \\
\text { Ac:=47.762 - sqr(b-3.555)/0.224; } \\
\text { Nmb:=trunc(TLst - TFrst)/TStep; } \\
\text { TStep:=(TLst - TFrst)/Nmb; } \\
\text { SetLength(ModelArr, Nmb); } \\
\text { for I:=0 to Nmb do } \\
\text { begin // calculate the model } \\
\text { At:=I*TStep; } \\
\text { ModelArr[l]:=(R0-Ri) }{ }^{*} \exp (-(\text { At } \\
\text { end; } \\
\text { WorldPaintBox1.DRAW_Exponer }\end{array}$ & $\begin{array}{l}\text { // initial resistance } \\
\text { // asymptote of the graph } \\
\text { // acidity correction parameter } \\
\text { // acid constant of the process } \\
\text { // number of points in acid range } \\
\text { // new step } \\
\text { // define the array length } \\
\text { Beta)/Ac) + Ri; } \\
\text { ModelArr);// draw the model graph }\end{array}$ \\
\hline
\end{tabular}

Graphs of the lines for the fermentation break are on Figure 5.

Figure 3. Algorithm for calculation and visualization of the model graph 


\section{IRTITE}

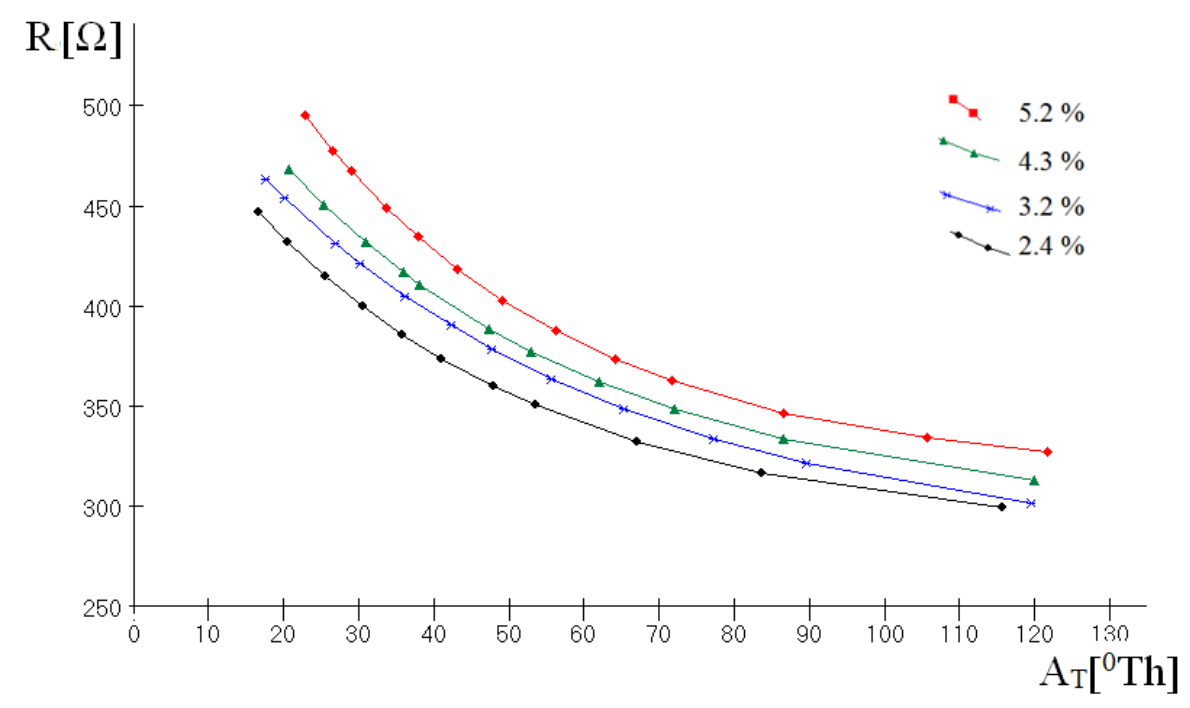

Figure 4. Exponential relationship models between electrical resistance and acidity

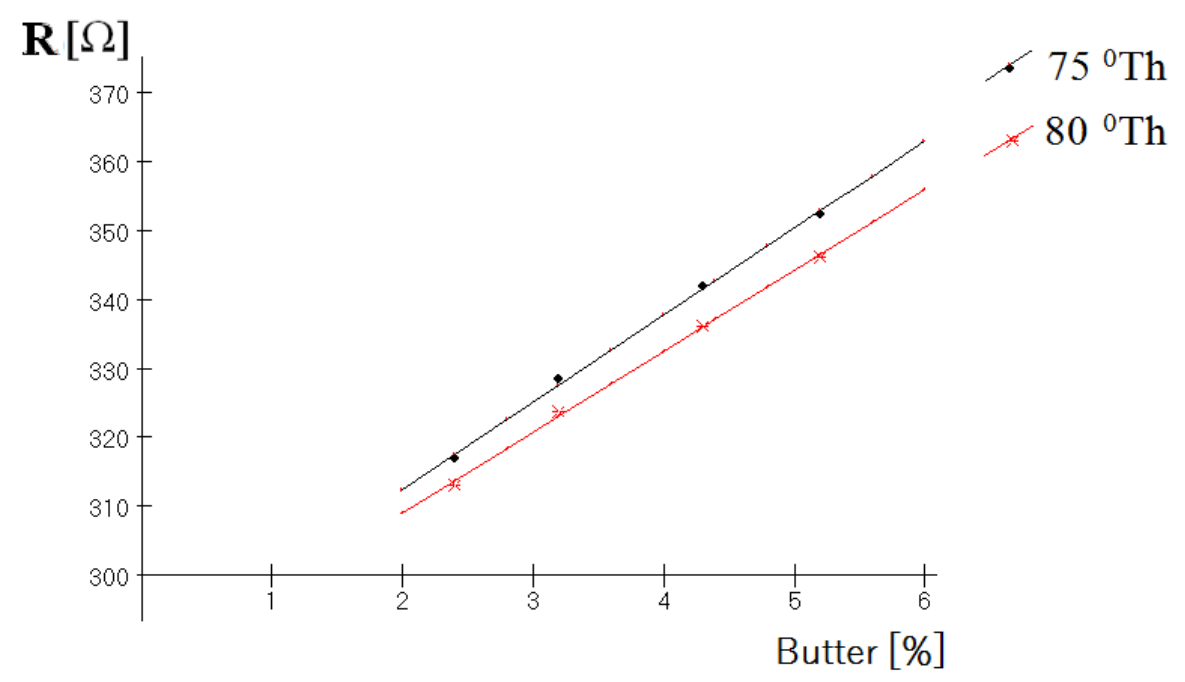

Figure 5. Range of fermentation break in function on the butterfat content

\section{EXAMPLE}

On the Bulgarian market a wide range of lactic acid products with the different butterfat content is offered. Kinds of yogurt with a fat content of $2 \%, 2.9 \%, 3.6 \%$ and $5.5 \%$ are the most common and consumed. The model of change in resistance of these yogurts as a function of titratable acidity is in Figure 6. 


\section{IRTITIE

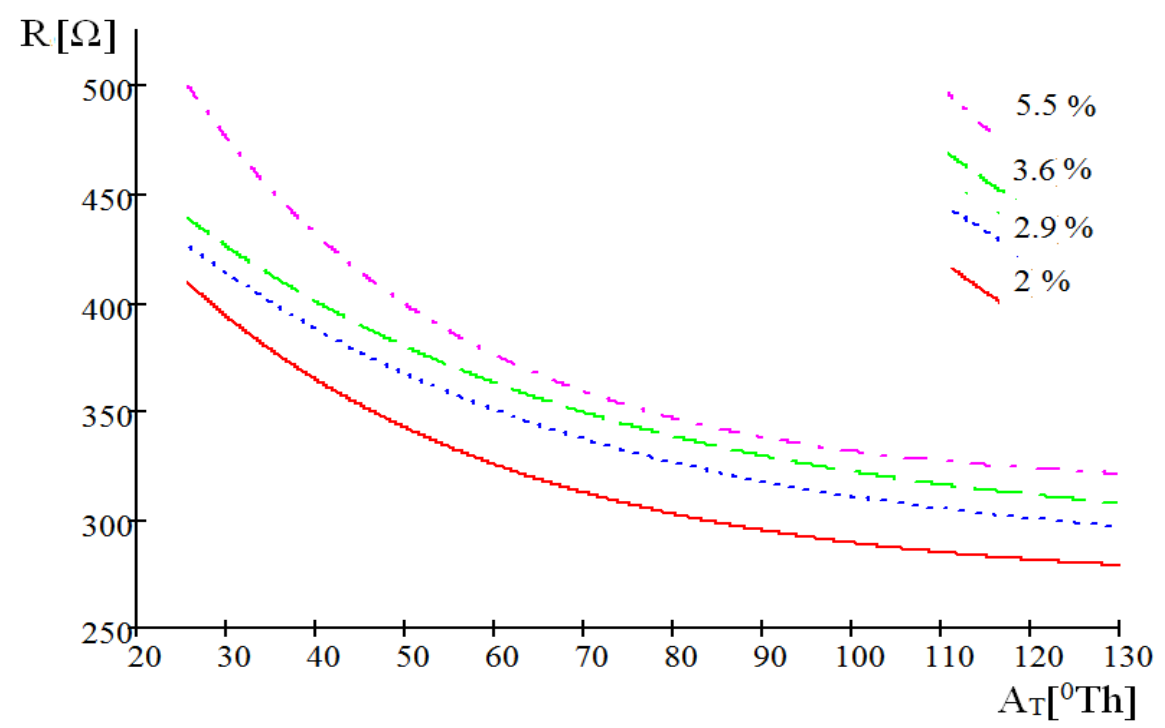

Figure 6. Relationship between electrical resistance and acidity of marketed milk

In Table 2 are the ranges of titratable acidity for stopping the lactic acid fermentation, calculated according to the formula (5).

Table 2. Resistance of the milk for the limits of the titratable acidity

\begin{tabular}{|c|c|c|c|c|}
\hline \multirow{2}{*}{ Titratable acidity $\left[{ }^{\circ} \mathrm{Th}\right]$} & \multicolumn{4}{|c|}{ Butter content [\%] } \\
\cline { 2 - 5 } & 2 & 2.9 & 3.6 & 5.5 \\
\hline 80 & 309.0 & 319.6 & 327.8 & 350.2 \\
\hline 75 & 312.5 & 323.8 & 332.7 & 356.7 \\
\hline
\end{tabular}

\section{CONCLUSIONS}

In the article, a model of change of the active impedance of the milk medium under conditions of lactic acid fermentation, as a function of titratable acidity and butterfat content is identified.

Formulas determining the range of resistance as a function of the fat content, for breaking lactic acid fermentation are brought out.

A program module for calculating and displaying graphs of simulated processes for any fat content is created.

The fermentation processes are simulated and the range to break the lactic acid fermentation of four types of milk distributed in the Bulgarian market are defined.

\section{ACKNOWLEDGMENTS}

This study was supported by Grant 3ФТT/30.04.2015 "Identification and Simulation of Second-order Dynamic Models" from the Faculty of Technics and Technologies of Yambol, Trakia University, Bulgaria. 


\section{REFERENCES}

[1] BDS 12:2010 Bulgarian Yogurt. Bulgarian Institute for Standardization. Sofia, 2010.

[2] Pannell L., Tonya C. Schoenfuss. (2007). Yogurt. Handbook of Food Products Manufacturing. Editor Y. H. Hui. Published by John Wiley \& Sons, Inc., Hoboken, New Jersey. V2. pp. 647-676.

[3] Ramesh C. Chandan. (2007). Functional Properties of Milk Constituents. Handbook of Food Products Manufacturing. Editor Y. H. Hui. Published by John Wiley \& Sons, Inc., Hoboken, New Jersey. V1. pp. 971-987.

[4] Vasilev M., Nikolov Kr. (2016). Impedance Method of Measuring of the Titratable Acidity of Yogurt. ARTTE Applied Researches in Technics, Technologies and Education. Vol. 4, No. 2. pp.133-138. ISSN 1314-8788 (print), ISSN 1314-8796 (online).

[5] Yankov K. (1999). Object Oriented Two-Dimensional Graphics in a Borland Delphi Environment. Proc. 13-th Int.Conf. SAER'99, sept.18-19, 1999, St.Constantine and Elena resort, Varna, Bulgaria, ISBN 954-438-248-8, pp. 169-173.

[6] Yankov, K. (2006). System Identification of Biological Processes. Proc. 20-th Int.Conf. "Systems for Automation of Engineering and Research (SAER-2006). St. Konstantin resort, sept.22-24, Varna, Bulgaria.

[7] Yankov, K. (2008). Simple Expression Language for Model Identificaton. Proc. of the Int. Conference on Information Technologies (InfoTech-2008). Constantine and Elena resort, sept.19-21, 2008, Varna, Bulgaria, vol.2, pp. 259-266.

[8] Yankov, K. (2009). Recognition and Function Association of Experimental Data. Proc. of the Int. Conference on Information Technologies (InfoTech-2009). St.Constantine and Elena resort, sept.17-20, Varna, Bulgaria.pp.131-140. ISBN 978-954-438-771-6.

[9] Yankov K. (2010). Decision Planning of System Identification. Proc. of the Int. Conference on Information Technologies (InfoTech-2010). Constantine and Elena resort, sept.16-18, 2010, Varna, Bulgaria, pp.229-238. ISSN 1314-1023.

[10] Yankov K. (2010). Preprocessing of Experimental Data in Korelia Software. Trakia Journal of Sciences. 2010; Vol. 8, Suppl. 3, pp. 41-48.

[11] Yankov, K. (2014). Model Identification in Some Biochemical Analytical Tests. Applied Researches in Technics, Technologies and Education, 2014, vol.2, No3, pp.267-276. ISSN 1314-8788 (print), ISSN 1314-8796 (online).

[12] Yankov K. (2015). Assessment of Processes Using Identification Models. Applied Researches in Technics, Technologies and Education ARTTE, Vol. 3,No.1, 2015. ISSN 1314-8788 (print), ISSN 1314-8796 (online). pp.52-60. DOI: 10.15547/artte.2015.01.006.

[13] Yankov K., Ilieva D. (2015). User Interface for Analysis of Experimental Data. Trakia Journal of Sciences, Vol. 13, Suppl. 1, pp 420-425, 2015 ISSN 1313-7069 (print), ISSN 1313-3551 (online) doi:10.15547/tjs.2015.s.01.072.

[14] Yankov K. (2015). Selection of the Approximating Function for Isobologram Modeling. Proc. Int. Conference on Information Technologies (InfoTech-2015). St.Constantine and Elena resort, Varna, Bulgaria, sept.17-19, 2015. pp.174-183. ISSN 1314-1023.

[15] Zlatev Zl., Petev M., Dimitrova A., Simeonova V., Dinev S., Dineva J. (2015). Analysis of methods and tools for evaluation the quality of yogurt, Journal of Innovation and entrepreneurship, year III, vol.1-2, 2015, pp.41-57, ISSN 1314-9180. 